\title{
Evaluating Social Support-Like Phenomena in an Animal Model of Posttraumatic Stress Disorder (PTSD) \\ Christoph K Thoeringer ${ }^{1,2}$ and Carsten T Wotjak ${ }^{2}$ \\ ${ }_{1}$ II Med. Klinik, Klinikum rechts der Isar, Technical University of Munich, Germany \\ ${ }^{2}$ Max Planck Institute of Psychiatry, Munich, Germany
}

\begin{abstract}
Social interactions contribute significantly to emotional regulation and, hence, foster resilience for psychopathological states and diseases. In particular, social support is supposed to buffer the development and distress in Posttraumatic Stress Disorder (PTSD). In the present study, we investigated the effect of different adult social housing conditions, i.e., socially isolated vs. paired housing in dyads, and the presence of social support regarding development and maintenance of PTSD-like symptoms in a mouse model of PTSD. In a first analysis, we could not detect effects of single versus dyad housing of male mice on unconditioned anxiety, acoustic startle reactivity or sensitized and conditioned long-term fear. However, mice housed in dyads displayed enhanced extinction of contextual fear 1 month after trauma. In a second analysis, we did not find evidence for social support-like phenomena among dyad housed animals, if traumatized mice were cohabited with a non-traumatized animal.
\end{abstract}

In summary, we could not detect social support-like phenomena among dyad housed male mice on the development and expression of PTSD-like symptoms in an animal model, but impaired extinction of remote contextual fear in singlehoused mice.

Keywords: Posttraumatic stress disorder; Animal model; Social animal housing; Social support; Anxiety

\section{Introduction}

Social interactions at the level of support, cognition and attachment may contribute to emotional regulation and, if disturbed or absent, to the development of mental disorders. In addition to human depression and anxiety disorders [1], several studies have been published emphasizing social components in Posttraumatic Stress Disorder (PTSD) [2]. In particular, social support-like phenomena have drawn most attention presuming that support helps buffering against psychological distress. Meta-analyses examining risk factors of PTSD found that either the lack of social support or actively perceiving support both before and after a traumatic event are among the strongest predictors of PTSD diagnosis or symptoms $[3,4]$. Additionally, an inverse relationship between enhanced social support and suicidal behaviour has been observed in PTSD populations $[5,6]$. However, the processes underlying the effects of social context and support on development and maintenance of the disorder have only been sparsely investigated [7].

Apart from human studies, substantial knowledge on the neurobiology of social behavior has been gathered in experiments using laboratory animals. Rats and mice are thought to be social animals. Hence, prolonged isolation of animals, for instance by individual housing, is frequently considered as a model of chronic stress as it induces abnormalities in behavior and neurochemistry leading to the theory of the "isolation syndrome" in mice [8]. Reports on social isolation in rodents provide evidence for, e.g., increased anxiety-related behavior [9], anhedonia-like symptoms [10], increases in alcohol intake [11] and aggression [12]. In addition, the social environment also exerts physiological consequences. For instance, solitary housing induces reduced corticolimbic allopregnanolone levels [13], a down-regulation of serotonergic neurotransmission [14] and impaired hippocampal neurogenesis [15]. On the other hand, these findings strongly suggest a beneficial outcome of group or colony housing on animal behavior. Hence, social housing might favour alleviated emotional responses in potentially aversive situations by empathy-like phenomena among rodents [16-18].
In recent years, we have established a mouse model of PTSD $[19,20]$ incorporating major criteria of the disease, i.e., symptoms of re-experiencing, hypervigilance, avoidance and emotional numbing [21,22]. A major psychobiological concept of PTSD assumes that both fear conditioning and sensitization processes contribute to the development and maintenance of the disorder [23]. Mice receiving a single, inescapable electric foot shock develop strong traumaassociated contextual fear as well as non-associative, stress-related fear (i.e., freezing to a neutral tone) [24], hyperarousal [25] and avoidance behavior [26]. Intriguingly, these two components become manifest with the passage of time and seem to represent independent behavioral dimensions $[24,25,27,28]$.

Regarding social factors, we could demonstrate the importance of the early postnatal social context in terms of maternal experience on the susceptibility to develop PTSD- like symptoms in mice [27]. Yet, there seems to be also a significant genetic component of individual susceptibility since the strain-dependent expression levels of PTSD-like symptoms persisted inter-strain embryo transfers [29]. In adulthood, enriched housing decreased the intensity of trauma-associated contextual fear and compensated for trauma-related volume loss of the hippocampus in our PTSD mouse model [30].

Expanding the analysis of the effects of early-life social conditions on the individual susceptibility for developing PTSD, the present study was aimed to investigate the impact of the social context in adulthood.

${ }^{*}$ Corresponding author: Christoph K Thoeringer, II Med. Klinik, Klinikum rechts der Isar, Technical University of Munich, Ismaninger Strasse 22, 81675 Munich, Germany, Tel.: +49-89-4140-2251; E-mail: christoph.thoeringer@Irz.tum.de

Received October 24, 2013; Accepted December 13, 2013; Published December 16,2013

Citation: Thoeringer CK, Wotjak CT (2013) Evaluating Social Support-Like Phenomena in an Animal Model of Posttraumatic Stress Disorder (PTSD) J Depress Anxiety 3: 143. doi:10.4172/2167-1044.1000143

Copyright: (C) 2013 Thoeringer CK, er al. This is an open-access article distributed under the terms of the Creative Commons Attribution License, which permits unrestricted use, distribution, and reproduction in any medium, provided the original author and source are credited. 
(i) We first analyzed whether either socially isolated (i.e., single) or dyad (i.e., paired) housing of adult male animals alters the susceptibility of mice for developing PTSD-like symptoms after exposure to a single aversive foot shock. (ii) As there is evidence for a social modulation and buffering of aversive experiences in rats and mice suggesting empathylike phenomena in rodents [16-18], we examined whether cohabitation of shocked and non-shocked mice could mitigate associative and/ or non-associative fear responses in our PTSD model. (iii) Finally, we performed several complementary behavioral tests to investigate additional anxiety-related parameters characterizing the PTSD-like phenotype in these mice such as avoidance behavior of aversive places (e.g., open arms of an elevated plus-maze test and the light compartment of a dark/light test arena) or hyperarousal as assessed by the strength of the acoustic startle reflex.

\section{Methods}

\section{Animals}

A total number of 70 male C57BL/6NCrl mice were used. Mice were purchased from Charles River Germany (Sulzfeld, Germany) at an age of 4 weeks and housed in groups of $4-5$ mice per cage upon arrival until an age of 6 weeks.

Thereafter, mice were separated in either individually housed animals (single housing) or in pairs consisting of two animals per cage (dyad housing). Mice of both groups were kept in parallel under identical standard housing conditions in the animal facility of the Max Planck Institute (i.e., Makrolon type II cages with sawdust bedding, inverse 12:12h light-dark schedule with lights off at 09:00h, at $22 \pm$ $2^{\circ} \mathrm{C}$ room temperature and $55 \pm 5 \%$ humidity). Water and food were provided ad libitum. Animals were allowed to habituate to the novel housing conditions for another 3 weeks before starting the experiment.

All experimental procedures were approved by the local governmental body and performed in accordance with the guidelines for the care and use of laboratory animals set by the European Community Council (86/609/CEE).

\section{Foot shock application and tests of conditioned and sensitized fear}

The experimental setup and procedure has been previously described in detail $[19,20,31]$. Briefly, experiments were performed in two different contexts: Foot shock application and testing for conditioned contextual fear was done in a mouse conditioning chamber that has a cubic shape with two metal and two Plexiglas walls and a metal grid floor. Sensitized fear was assessed in a neutral context consisting of a Plexiglas cylinder with sawdust as bedding. Both contexts were cleaned with detergents of different odours (conditioning chamber: $70 \%$ ethanol; neutral context: $1 \%$ acetic acid).

For shock application, animals were placed into the conditioning chamber, and after 198sec a scrambled foot shock ( 2 sec duration, $1.5 \mathrm{~mA}$ current intensity) was delivered via the metal grid. Animals remained in the conditioning chamber for an additional $60 \mathrm{sec}$ before they were returned to their home cages. For measurements of sensitized fear, mice were placed in the neutral test context, and after $180 \mathrm{sec}$ a $3 \mathrm{~min}$ neutral tone $(80 \mathrm{~dB}, 9 \mathrm{kHz})$ was presented to the animals. Conditioned fear was tested by exposing the animals to the conditioning chamber for $3 \mathrm{~min}$ without delivery of a second foot shock. As a measure of fear, we assessed freezing behavior defined as the absence of all movements except for respiration and the animal's head remaining in a horizontal position. Freezing data were averaged to $3 \mathrm{~min}$ intervals and presented as percentage of the analysis interval.

\section{Dark/light avoidance test}

Mice were tested in a box $(45 \times 20 \times 25 \mathrm{~cm})$ that was divided into two compartments: A light compartment that was brightly illuminated with 300lux (comprising 2/3 of the arena) and a dark, non-illuminated area. Walls and floor of the light compartment were made of white PVC plastic, whereas the dark compartment consisted of black PVC walls and a black floor. The two parts were separated by plastic walls and connect by a $5 \mathrm{~cm}$ tunnel. For testing, animals were placed into the center of the dark compartment and their behavior was recorded on DVDs during a $5 \mathrm{~min}$ test session. After each session, animals were returned to their home cages and the arena was cleaned with water containing liquid soap. The following behavioral parameters were considered: the number of entries into the light compartment and the total time spent in the light vs. the dark compartment or the tunnel of the test arena. A valid entry was counted when the animal went into the compartment with all four paws.

\section{Elevated Plus-Maze (EPM) test}

The apparatus had two open $(30 \times 5 \mathrm{~cm})$ and two closed $(30 \times 5 \times 15$ $\mathrm{cm})$ arms connected by a central platform $(5 \times 5 \mathrm{~cm})$ and was elevated $40 \mathrm{~cm}$ above the floor. All parts were made of white PVC plastic. The illumination of the maze was adjusted to yield 300lux in the open arms and only 5lux in the closed areas. Behavioral testing was performed for 5 min with animals initially being placed onto the center of the maze facing one of the closed arms. At the end of the experiment, animals were returned to their home cages and the maze was carefully cleaned with soap followed by clear water and drying. Each session was recorded on DVD for the analysis of the following parameters: total number of entries into and time spent in the open and closed arms. A valid entry was defined by the four paws - criteria (see above).

\section{Test of the Acoustic Startle Response (ASR)}

The ASR reflects a transient motor response to a sudden unexpected stimulus such as a loud noise. We measured it in four identical mouse test chambers consisting of Plexiglas cylinders (inner diameter $4 \mathrm{~cm}$, length $8 \mathrm{~cm}$ ) mounted on a plastic platform essentially as described previously [25]. In brief, each cylinder was located in a sound attenuated chamber (SR-LAB, San Diego Instruments, CA). The movement of an animal within the cylinder was detected by a piezoelectric element mounted under each platform, and the voltage output was further amplified and then digitized (sampling rate $1 \mathrm{kHz}$ ) by a computer interface. The startle amplitude was defined as the peak voltage output within the first $50 \mathrm{~ms}$ after stimulus onset. To insure identical output levels for each chamber the response sensitivity was calibrated before startle measurement.

Startle stimuli and background noise were delivered through a high-frequency speaker placed $20 \mathrm{~cm}$ above each cage. The 6 different startle stimuli consisted of white noise bursts of $20 \mathrm{~ms}$ duration and 75 , $85,95,105,115$ and $120 \mathrm{~dB}$ intensities, respectively, and were presented in a constant background noise of $50 \mathrm{~dB}$. The intensity was measured using an audiometer (Radio Shack, 33-2055). On control trials only background noise was present. After a habituation period of $5 \mathrm{~min}, 10$ control trials and 20 startle trials including stimuli at various intensities were presented in a pseudo-random order. The inter- stimulus interval was $15 \mathrm{sec}$ on average (i.e., 13-17 sec, random order).

\section{Experimental procedures}

As presented in Figure 1A, the experimental design included six groups of animals that received a foot shock $(+)$ or remained in their home cages (no shock) and were single housed or in dyads: (i) single 


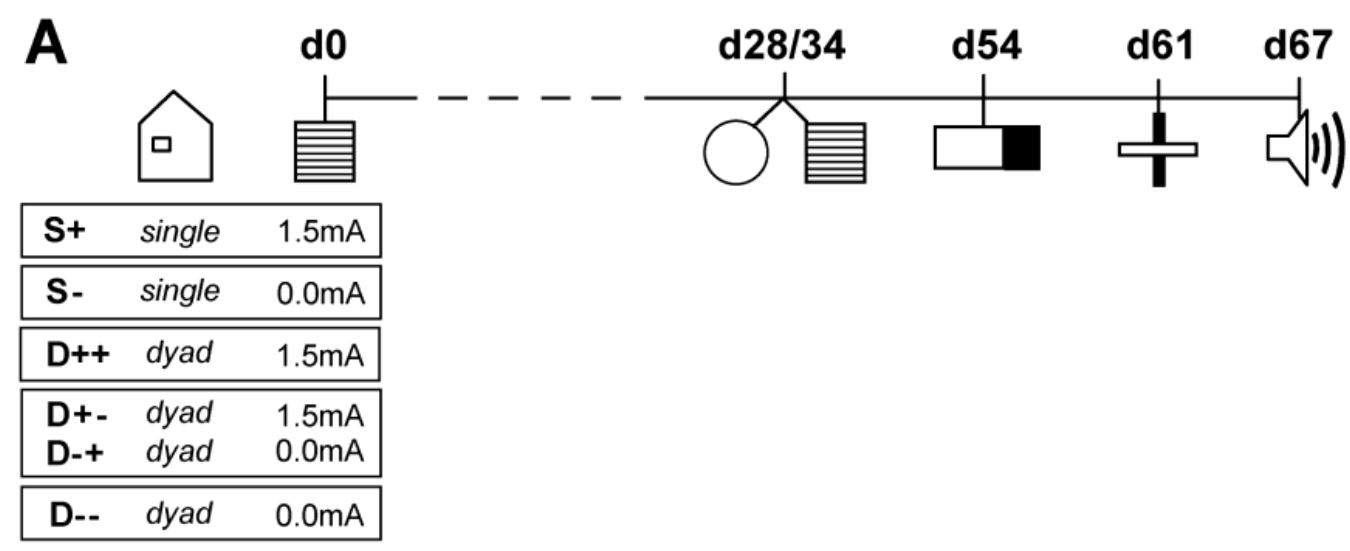

B

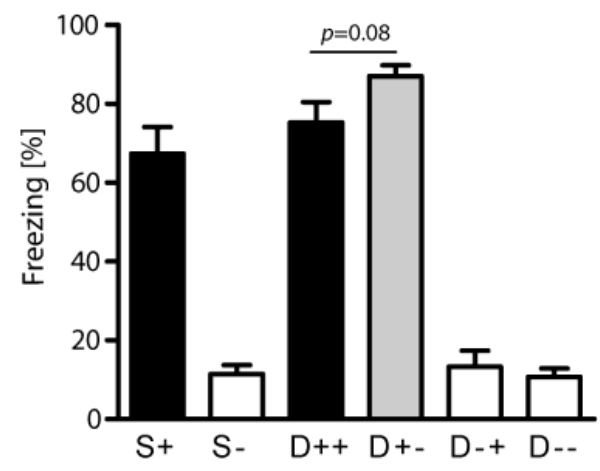

D

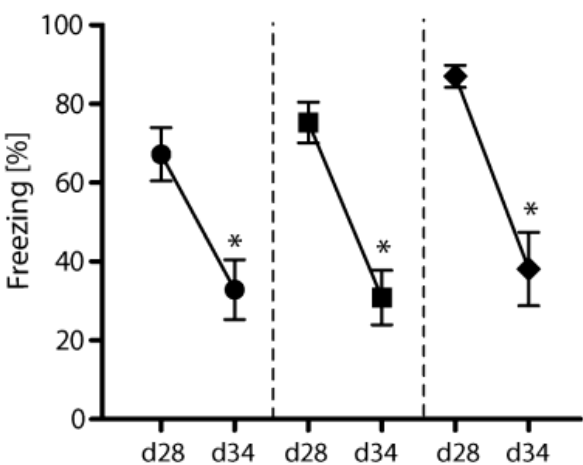

C

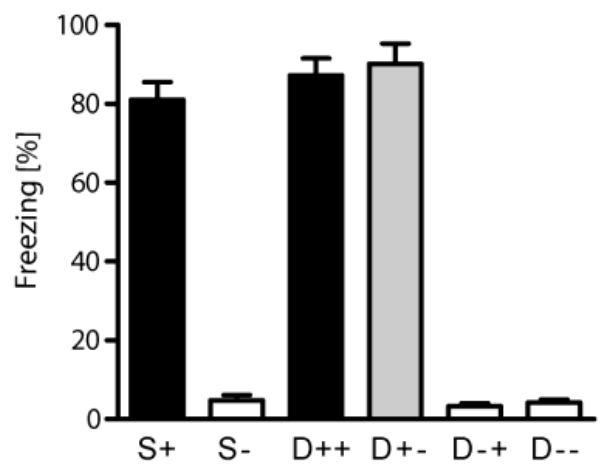

$\mathbf{E}$

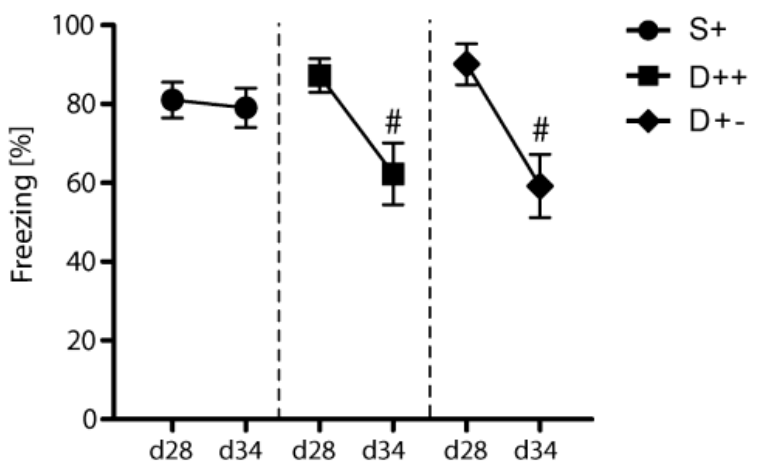

Figure 1: Sensitized and contextual fear in an animal model of PTSD as a function of shock and housing conditions. (A) Mice were randomly assigned to 6 groups ( $n=10-14 /$ group). Mice were single housed and received an inescapable foot shock (2sec, 1.5mA) on day 0 ( $S+$ ), another group of single housed mice remained non-shocked (S-). Mice of the other groups were housed in pairs (dyad) with either both of them (D++), only one of them (D+-) or none of them (D--) receiving a shock (note that we also analyzed the behavioral performance of the non-shocked cage mates of D+-, i.e. D-+). 4 and 5 weeks later (i.e., days 28 and 34 ), all mice were first exposed to a $3 \mathrm{~min}$ tone in a neutral test context $(O)$ and then to the shock context (目). Animals were further exposed to a dark/light avoidance test (day 54 ), to the elevated plus maze test (day 61) and to the acoustic startle response test (day 67). Freezing responses to the neutral tone (B) and the shock context (C) on day 28. Change of freezing responses during repetitive tone (D) or context exposure (E). Data are presented as mean \pm s.e.m. of freezing behavior shown as percentage over a 3 min-tone or -context exposure. \#p $<0.05 \mathrm{~d} 28 \mathrm{vs}$. d34 (Newman-Keuls posthoc test), ${ }^{*}<0.05 \mathrm{~d} 28 \mathrm{vs}$. d34 (ANOVA with repeated measurements) 
housing and foot shock administration $[\mathrm{S}+]$ ( $\mathrm{n}=11$ mice), (ii) single housing and no foot shock $[\mathrm{S}](\mathrm{n}=11$ mice), (iii) dyad housing with both animals receiving a foot shock $[\mathrm{D}++]$ ( $\mathrm{n}=14$ mice/7 dyads), (iv) dyad housing with only one animal receiving a foot shock [D+-] $(n=11$ mice/11 dyads), (v) cage mate of the dyad (iv) that did not receive the foot shock [D-+] ( $\mathrm{n}=11$ mice/11 dyads), and (vi) dyad housing with no animal being shocked [D--] ( $\mathrm{n}=10$ mice/5 dyads).

In detail, animals were shocked on day 0 . Four weeks later (day 28), animals were tested for sensitized and conditioned fear. On day 34 , testing for sensitized and conditioned fear was repeated to determine desensitization- and extinction-like processes. After another three weeks, additional anxiety parameters were assessed using the light/dark avoidance test (day 54) and the EPM (day 61). Finally, on day 67, ASR was determined as a measure of animal hyperarousal.

All experiments were performed during the activity phase of the animals (between 10:00h and 18:00h). Freezing behavior, anxiety-like behaviors and startle responses were measured in different testing rooms in order to prevent context generalization. The animals' behavior during each test was recorded on DVDs (except for the ASR test), and later scored off-line by a trained observer blind to the experimental condition using a customized freeware software (EVENTLOG by Robert Henderson, 1986).

\section{Data analysis}

For analysis of behavioral components of single vs. group housing, factorial analyses of variance (ANOVAs) were employed with shock and housing (i.e., experimental groups $\mathrm{S}+, \mathrm{S}-, \mathrm{D}++, \mathrm{D}--)$ as betweensubject factors. In case of the analyses of desensitization and extinctionlike processes in fear conditioning experiments or of ASR experiments, we performed an ANOVA with repeated measurements were we included housing (single vs. dyad housing), extinction (day 28 vs. day 34 ), support (D++ vs. D+- mice) or intensity as additional withinsubject factor. Post hoc comparisons were performed using NewmanKeuls tests. For analyses of behavioral consequences of social support (D+- vs. D++), two-group comparisons were performed with t-tests for independent groups (unpaired t-test) or by means of ANOVAs with repeated measurements.

Statistical analyses were performed using GraphPad Prism 5.0 (GraphPad, CA), Statistica 5.0 (StatSoft, OK) and SPSS 16.0 (SPSS, IL). Statistical significance was accepted if $\mathrm{p}<0.05$.

\section{Results}

\section{Effects of housing conditions on sensitized and conditioned fear}

We first assessed the sensitization component of incubated fear by exposing the animals to a neutral context and measuring freezing to a neutral tone. Shocked mice displayed significantly higher levels of freezing 4 weeks after conditioning compared to controls $\left(\mathrm{F}_{\text {shock }(1,42)}=159.6, \mathrm{p}<0.001\right.$; Figure $\left.1 \mathrm{~B}\right)$, whereas housing did not affect freezing behavior $\left(\mathrm{F}_{\text {housing(1,42) }}=0.6, \mathrm{p}=0.45 ; \mathrm{F}_{\text {shock }}\right.$ housing $\left.(1,42)=0.8, \mathrm{p}=0.36\right)$. To assess whether social support alleviates fear sensitization, we compared freezing levels between animals of group $\mathrm{D}+-$ vs. $\mathrm{D}++$. Intriguingly, shocked mice whose cage mates did not receive a foot shock (i.e., D+- group) showed even nominally increased tone freezing compared to mice of the $\mathrm{D}++$ group $(\mathrm{t} 23=1.8 ; \mathrm{p}=0.08)$.

We next tested the animals for contextual fear by exposing them to the shock context. We observed significantly higher freezing in the shocked vs. control animals $\left(\mathrm{F}_{\text {shock }(1,42)}=503.5, \mathrm{p}<0.001\right.$; Figure $\left.1 \mathrm{C}\right)$, whereas housing had no significant effect $\left(\mathrm{F}_{\text {housing(1,42) }}=0.6, \mathrm{p}=0.44\right.$; $\left.\mathrm{F}_{\text {shock }^{*} \text { housing }(1,42)}=1.0, \mathrm{p}=0.33\right)$. Social support failed to affect contextual fear ( $\mathrm{D}+$ - vs. $\mathrm{D}++$ mice: $\mathrm{t} 23=0.4, \mathrm{p}=0.67)$. Mice were re-exposed to the neutral test chamber and tone and to the conditioning context one week later (i.e., experimental day 34) in order to assess whether different shock and housing conditions modulate desensitization and extinctionlike processes. Shocked mice displayed a significant decrease in freezing behavior during the second tone presentation (ANOVA with repeated measurements, S+, D++, D+-: $\mathrm{F}_{\text {extinction(1,34) }}=61.5, \mathrm{p}<0.001$; Figure 1D), whereas single or dyad housing had no effect $\left(\mathrm{F}_{\text {housing(1.34) }}=1.0, \mathrm{p}=0.32\right.$; $\mathrm{F}_{\text {extinction*housing(1,34) }}=1.6, \mathrm{p}=0.22$ ). In terms of contextual fear (Figure 1E), single housed animals showed almost no extinction of contextual fear from day 28 to day 34 compared to shocked, dyad housed mice which displayed significantly reduced freezing to the shock context on day $34\left(\mathrm{~F}_{\text {extinction*housing }(1,33)}=9.1, \mathrm{p}=0.005\right)$. No differences in tone and context extinction could be observed between $\mathrm{D}++$ and $\mathrm{D}+$ - animals (tone freezing: $\mathrm{F}_{\text {support }(1,23)}=2.7, \mathrm{p}=0.12$; context freezing: $\mathrm{F}_{\text {support }(1,22)}=0.02$, $\mathrm{p}=0.91)$.

\section{Effects of housing conditions on unconditioned anxiety}

Dark/light avoidance test: Shocked animals entered the light compartment less frequently than non-shocked mice $\left(\mathrm{F}_{\text {shock }(1,40)}=14.1\right.$; $\mathrm{p}=0.001$; Table 1 ), while housing per se did not alter these transitions

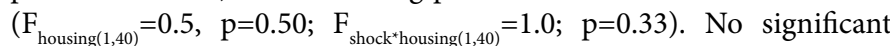
effects of shock or housing could be detected for the time the mice spent in the light or dark compartment as well as the tunnel of the test arena (time in light compartment: $\mathrm{F}_{\text {shock }(1,40)}=1.6, \mathrm{p}=0.21 ; \mathrm{F}_{\text {housing }(1,40)}=0.4$, $\mathrm{p}=0.55 ; \mathrm{F}_{\text {shock }}$ housing(1,40)$=0.2, \mathrm{p}=0.66$; time in dark compartment: $\mathrm{F}_{\text {shock }(1,40)}=3.9, \quad \mathrm{p}=0.06 ; \quad \mathrm{F}_{\text {housing }(1,40)}=0.2, \quad \mathrm{p}=0.88 ; \quad \mathrm{F}_{\text {shock housing }(1,40)}=1.2$, $\mathrm{p}=0.29 ;$ time in the tunnel: $\mathrm{F}_{\text {shock }(1,40)}=1.8, \mathrm{p}=0.18 ; \mathrm{F}_{\text {housing }(1,40)}=0.7$, $\left.\mathrm{p}=0.41 ; \mathrm{F}_{\text {shock }} \mathrm{w}^{*}=1.0 ; \mathrm{p}=0.33\right)$. Social support by a non-shocked cage mate failed to significantly change light avoidance (D++ vs. D+-:

\begin{tabular}{|c|c|c|c|c|c|c|}
\hline Test & Experimental groups & & & & & \\
\hline DL Test & $S^{+}$ & S- & $\mathrm{D}++$ & $\mathrm{D}+-$ & D-+ & D-- \\
\hline Entries light comp. (\#) & $2.5 \pm 0.9$ & $6.8 \pm 1.1$ & $2.8 \pm 0.8$ & $5.5 \pm 1.2$ & $6.2 \pm 1.0$ & $5.3 \pm 0.8$ \\
\hline Time light comp. (sec) & $47.2 \pm 14.3$ & $69.7 \pm 11.3$ & $45.1 \pm 15.0$ & $71.5 \pm 14.2$ & $63.0 \pm 10.3$ & $55.9 \pm 9.0$ \\
\hline Time dark comp. (sec) & $236.9 \pm 15.7$ & $184.8 \pm 13.1$ & $215.9 \pm 22.5$ & $202.9 \pm 17.2$ & $202.9 \pm 12 . .2$ & $207.3 \pm 6.7$ \\
\hline Time tunnel (sec) & $15.9 \pm 4.9$ & $45.5 \pm 7.0$ & $39.0 \pm 19.8$ & $25.6 \pm 4.1$ & $34.1 \pm 3.2$ & $43.5 \pm 2.7$ \\
\hline \multicolumn{7}{|l|}{ EPM-test } \\
\hline Entries open arms (\#) & $2.2 \pm 0.6$ & $3.9 \pm 0.9$ & $2.9 \pm 0.5$ & $4.2 \pm 0.8$ & $2.6 \pm 0.7$ & $1.9 \pm 0.6$ \\
\hline Entries closed arms (\#) & $4.9 \pm 1.8$ & $11.6 \pm 1.3$ & $4.5 \pm 1.3$ & $3.1 \pm 1.2$ & $13.2 \pm 0.9$ & $9.4 \pm 1.4$ \\
\hline Time open arms (sec) & $128.9 \pm 38.6$ & $50.7 \pm 13.9$ & $131.9 \pm 33.1$ & $174.1 \pm 31.3$ & $22.9 \pm 8.1$ & $21.0 \pm 15.0$ \\
\hline Time closed arms (sec) & $97.7 \pm 33.9$ & $193.2 \pm 13.9$ & $110.3 \pm 27.9$ & $65.9 \pm 23.4$ & $204.9 \pm 13.6$ & $206.6 \pm 15.8$ \\
\hline Total arm entries (\#) & $7.1 \pm 1.9$ & $15.5 \pm 1.5$ & $7.4 \pm 1.5$ & $7.3 \pm 1.8$ & $15.8 \pm 1.2$ & $11.3 \pm 0.9$ \\
\hline
\end{tabular}

Table 1: Unconditioned anxiety behaviors in a dark/light (DL) - or the Elevated Plus Maze (EPM) - test. Data are presented as mean \pm s.e.m., \# presents number of entries. For statistical analyses see text. 
entries into the light compartment, $\mathrm{t}_{22}=1.9, \mathrm{p}=0.07$; time spent in the light compartment, $\mathrm{t}_{22}=1.3, \mathrm{p}=0.21$ ).

EPM. Surprisingly, shocked mice spent significantly more time on the open arms than non-shock controls $\left(\mathrm{F}_{\text {shock }(1,38)}=11.7, \mathrm{p}=0.002\right.$; Table 1), whereas shock-related differences could not be observed for entries into the open arms $\left(\mathrm{F}_{\text {shock }(1,38)}=0.2, \mathrm{p}=0.66\right)$. However, shocked mice showed an avoidance of closed arms compared to non-shocked controls (entries closed arms: $\mathrm{F}_{\text {shock }(1,38)}=15.1, \mathrm{p}<0.001$; time spent in closed arms: $\left.\mathrm{F}_{\text {shock }(1,38)}=13.6, \mathrm{p}=0.001\right)$. Mice having received a shock showed significantly less total arm entries $\left(\mathrm{F}_{\text {shock }(1,38)}=14.1, \mathrm{p}<0.001\right.$, Table 1). The housing conditions per se again failed to significantly affect behavior in any of the parameters studied (entries open arms: $\mathrm{F}_{\text {housing( } 1,38)}=0.9, \mathrm{p}=0.36 ; \quad \mathrm{F}_{\text {shock*housing }(1,38)}=3.7, \mathrm{p}=0.06 ;$ entries closed arms: $\mathrm{F}_{\text {housing( }(1,38)}=0.7, \mathrm{p}=0.39 ; \mathrm{F}_{\text {shock housing }(1,38)}=0.4, \mathrm{p}=0.55$; time in the open arms: $\mathrm{F}_{\text {housing }(1,38)}=0.2, \mathrm{p}=0.66 ; \mathrm{F}_{\text {shock }}$ housing( $(1,38)=0.3, \mathrm{p}=0.59$; time in closed arms: $\mathrm{F}_{\text {housing }(1,38)}=0.3, \mathrm{p}=0.62 ; \mathrm{F}_{\text {shock }}$ housing(1,38) $=0.0, \mathrm{p}=0.99$; total arm entries: $\left.\mathrm{F}_{\text {housing(1,38) }}=1.5, \mathrm{p}=0.23 ; \mathrm{F}_{\text {shock housing(1,38) }}=2.0, \mathrm{p}=0.16\right)$. Social support failed to significantly affect entries or time spent in the open arms (D++ vs. D+-: open arm entries: $\mathrm{t}_{23}=1.3, \mathrm{p}=0.21$; open arm time: $\mathrm{t}_{23}=1.1, \mathrm{p}=0.28$ ). Of note, 10 out of 34 shocked animals but only 2 out of 30 non-shocked mice jumped off the open arms during the test (Chi square $=5.412, \mathrm{p}=0.02$ ). Jumping automatically led to exclusion from further analysis.

\section{Effects on acoustic startle responses}

We finally investigated the effects of shock and housing on the ASR of mice on day 67 after trauma. We observed a significant shock effect $\left(\mathrm{F}_{\text {shock }(1,41)}=4.9 ; \mathrm{p}=0.03\right)$ and a significant interaction of the factors shock and intensity $\left(\mathrm{F}_{\text {shock }}\right.$ intensity $\left.(5,205)=2.3 ; \mathrm{p}=0.04\right)$. Post hoc comparisons revealed that shocked animals showed significantly higher startle responses at 105,115 and $120 \mathrm{~dB}$ compared to nonshocked controls (Figure 2). This effect, however, was independent of the housing conditions $\left(\mathrm{F}_{\text {shock }^{*} \text { intensity }}\right.$ housing $(5,205)=0.2, \mathrm{p}=0.95$; Figure 2$)$. Social support again failed to significantly impact on ASR (D++ vs. $\left.\mathrm{D}+-, \mathrm{F}_{\text {support(1,115) }}=0.2 ; \mathrm{p}=0.66\right)$.

\section{Discussion}

There is accumulating evidence suggesting that social support, social cognition and attachment both before and after a traumatic event represent major individual resilience factors for the development and maintenance of human PTSD [e.g., ref. 2]. Therefore, we first hypothesized that post-weaning individual housing of animals might induce exaggerated fear and anxiety-related behaviors in our animal model of PTSD when compared to dyad housed mice. Against our expectations, dyad housing per se did not attenuate the initial fear responses either to an unconditioned tone or to the conditioned context 4 weeks after foot shock exposure. However, dyad housed, but not single housed mice, showed extinction of contextual fear. Enhanced extinction occurred independent of whether both mice and only one animal of the dyad had been shocked. Desensitization-like processes (as revealed by reduced freezing during re-exposure to the unconditioned tone), however, could be observed in each group. These data underscore the well-known impact of rodent social housing on learning and memory in a variety of paradigms. For example, social isolation impairs place preference conditioning [32] or extinction of conditioned taste aversion [33], social memory [34] or contextual fear conditioning [35]. However, reports on the putative aversiveness of social isolation in rodents are ambiguous. Depending on several factors such as species, laboratory strain, gender as well as duration and timing of isolated housing and experimental procedures, contrasting findings have been published concerning isolation-induced sequelae on anxietylike behavior [9,36-39], despair-like behavioral deficits $[9,10]$ or activity of the stress hormone system [40]. Accordingly, single housed, nonshocked mice of the present study did not differ from pair housed non-shocked mice in any behavioral measure, including anxiety-like behavior shown in the light/dark avoidance or EPM test. As rats and mice are thought to be social mammals, transmission of emotional information to a conspecific has been repeatedly shown to influence rodent behavior or stress responses [41]. For instance, observation of a fearful rat or mouse induces distress and also fear-related behaviors in a conspecific $[18,42]$. Such process is known as observational learning of fear and occurs across species [43]. Similarly, recognizing a cage mate in pain increases the observer's pain sensitivity suggesting also empathy-like phenomena among rodents [16]. On the other hand, presence or interaction with a non-fearful conspecific is able to mitigate conditioned fear in rats $[44,45]$. Such phenomenon, referred to as social buffering, is frequently observed in situations where an animal has been

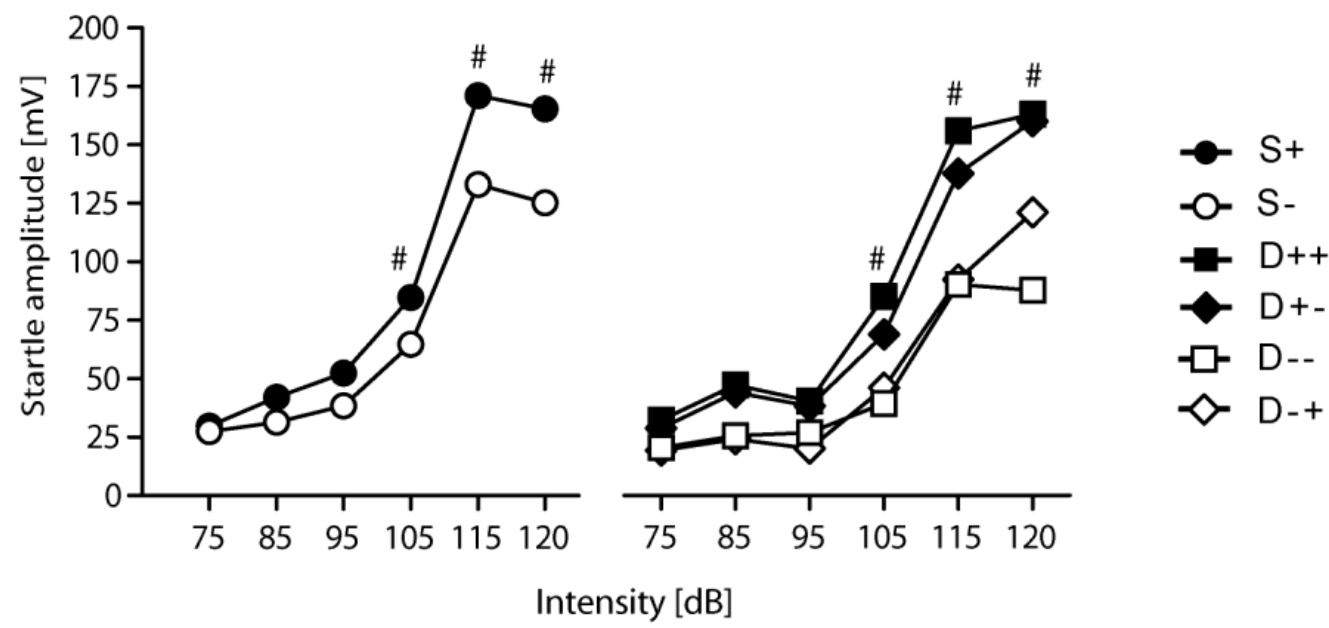

Figure 2: Acoustic startle responses as a function of shock and housing conditions. The startle response is presented as averaged startle amplitude elicited at six different intensities (i.e., sound pressure levels in $\mathrm{dB}$ ) at day 67. Data are displayed as means. \#p<0.05 S+ and D++ vs. S- and D-- (Newman-Keuls post hoc tests) 
housed with conspecifics after an aversive experience. Because of these findings, we further investigated whether social buffering affects the development, expression or maintenance of PTSD-like symptoms by comparing the behavior of dyads with two shocked mice vs. dyads with a shocked and non- shocked mouse. We failed to detect any significant difference for non-associative or associative fear responses between these dyad housed groups of mice. Instead, we even observed a nominal increase in freezing to the unconditioned tone in those shocked animals that were housed with non-shocked mates (i.e., D+-). So far, these data exclude a fear alleviating effect of our social housing conditions in the context of our PTSD model.

In a further series of behavioral analyses we investigated the impact of the foot shock and housing conditions on anxiety-related behaviors in the EPM- and the dark/light test. In the dark/light test, shocked animals spent significantly less time in the light compartment and made nominally fewer entries into it suggesting increased avoidance of the aversive compartment of the arena. This anxiogenic response was independent of social housing conditions. Unexpectedly, shocked mice spent significantly more time on the open, brightly lit arms of the EPM. At the same time, shocked mice did not only avoid the aversive zone of the apparatus, but avoided the closed, i.e. protected, arms. Usually, an increased open arm activity is interpreted as reduced anxiety-related behavior, for instance mediated by the action of anxiolytic drugs [46], whereas anxiogenic effects are thought to be indicated by reduced open arm time and entries. In light of these considerations, the increased open arm preference shown by conditioned animals was rather surprising. However, a plausible explanation of this paradox result might be the generalization of fear responses, which is associated with a vigorous inhibition of (locomotor) activity whenever the animals are exposed to a novel, potentially aversive context [26]. Interestingly, Radulovic et al. [47] reported a similar result of increased open arm preference and low locomotion on the EPM after contextual fear conditioning in mice. In contrast to the incubation period needed for the development of PTSDlike symptoms in mice, this effect may be attributed to the sensitization stress per se as it was observed already $24 \mathrm{~h}$ after the conditioning procedure and in animals that had received an immediate shock upon exposure to the conditioning context which precluded the formation of associative contextual fear memory.

Finally, we assessed the impact of shock sensitization on the acoustic startle response and found that shocked mice displayed increased acoustic startle. This effect was independent of social housing. Increased startle reactivity is suggested to be indicative of enhanced anxiety sensitivity and hyperarousal as a core symptom of PTSD [48]. Accordingly, several clinical studies reported a proneness of individuals suffering from PTSD to show exaggerated startle responses in threatening contexts $[49,50]$ which further supports the face validity of our PTSD mouse model.

This study has some limitations as we did not analyse the social organisation of the dyads. Thus, we can only speculated whether there is social buffering at all among male C57BL/6NCrl mice or whether it has no effect on PTSD-like symptoms. Potentially, high levels of territoriality and intolerance against a same-sex conspecific that occurs repeatedly among cohabitating adult males under laboratory housing conditions could prevent the occurrence of social buffering [39]. Moreover, we only considered same-sex (male) dyads. This leaves the question open whether mixed male/female dyads would ameliorate PTSD-like symptoms. In addition, our study did not consider distinguishing (theoretical) differences of empathy and social buffering that might occur between siblings, mating pairs or unrelated cage mates. However, several studies in mice did not observe differences in empathic fear or pain responses between strangers, cage mates or sibling [16,51], which speaks against a prominent role of the factor relatedness or familiarity.

In summary, social context appears to modulate basic aspects of the fear system in humans, and social support among humans is supposed to foster resilience. Although studies of social cognition, bonds and support in rats and mice repeatedly reported alleviating effects on anxiety or stress, we were not able to find social support-like buffering of PTSD-related symptoms by non-shocked or shocked cage mates. Because of the ecological characteristics of mice with a single male dominating the cohort and a large territory [52], future experiments should deal with the cohabitation of male and female animals to provide a more natural situation of social support.

\section{Acknowledgement}

The authors would like to thank I. Braun, V. Micale, C.P. Mauch, H. Reich and A. Mederer for excellent technical support

\section{References}

1. Heinrich LM, Gullone E (2006) The clinical significance of loneliness: a literature review. Clin Psychol Rev 26: 695-718.

2. Charuvastra A, Cloitre M (2008) Social bonds and posttraumatic stress disorder. Annu Rev Psychol 59: 301-328.

3. Brewin CR, Andrews B, Valentine JD (2000) Meta-analysis of risk factors for posttraumatic stress disorder in trauma-exposed adults. J Consult Clin Psycho 68: 748-766.

4. Ozer EJ, Best SR, Lipsey TL, Weiss DS (2003) Predictors of posttraumatic stress disorder and symptoms in adults: a meta-analysis. Psychol Bull 129 $52-73$

5. Jakupcak M, Vannoy S, Imel Z, Cook JW, Fontana A, et al. (2010) Does PTSD moderate the relationship between social support and suicide risk in Iraq and Afghanistan War Veterans seeking mental health treatment? Depress Anxiety 27: 1001-1005

6. Panagioti M, Gooding PA, Taylor PJ, Tarrier N (2014) Perceived social support buffers the impact of PTSD symptoms on suicidal behavior: Implications into suicide resilience research. Compr Psychiatry 55: 104-112.

7. Guay S, Billette V, Marchand A (2006) Exploring the links between posttraumatic stress disorder and social support: processes and potential research avenues. J Trauma Stress 19: 327-338.

8. Valzelli L (1973) The "isolation syndrome" in mice. Psychopharmacologia 31 305-320.

9. Võikar V, Polus A, Vasar E, Rauvala H (2005) Long-term individual housing in C57BL/6J and DBA/2 mice: assessment of behavioral consequences. Genes Brain Behav 4: 240-252.

10. Wallace DL, Han MH, Graham DL, Green TA, Vialou V, et al. (2009) CREB regulation of nucleus accumbens excitability mediates social isolation-induced behavioral deficits. Nature Neuroscience 12: 200-209.

11. Ehlers CL, Walker BM, Pian JP, Roth JL, Slawecki CJ (2007) Increased alcoho drinking in isolate-housed alcohol-preferring rats. Behav Neurosci 121: 111 119.

12. Pinna G, Dong E, Matsumoto K, Costa E, Guidotti A (2003) In socially isolated mice, the reversal of brain allopregnanolone down-regulation mediates the antiaggressive action of fluoxetine. Proc Natl Acad Sci U S A 100: 2035-2040.

13. Pibri F, Nelson M, Guidotti A, Costa E, Pinna G (2008) Decreased corticolimbic allopregnanolone expression during social isolation enhances contextual fear: a model relevant for posttraumatic stress disorder. Proc Natl Acad Sci USA 105: 5567-5572.

14. Heidbreder CA, Weiss IC, Domeney AM, Pryce C, Homberg J, et al. (2000). Behavioral, neurochemical and endocrinological characterization of the early social isolation syndrome. Neuroscience 100: 749-768.

15. Ibi D, Takuma K, Koike H, Mizoguchi H, Tsuritani K, et al. (2008) Social isolation rearing-induced impairment of the hippocampal neurogenesis is associated with deficits in spatial memory and emotion-related behaviors in juvenile mice. J Neurochem 105: 921-932. 
Citation: Thoeringer CK, Wotjak CT (2013) Evaluating Social Support-Like Phenomena in an Animal Model of Posttraumatic Stress Disorder (PTSD) J Depress Anxiety 3: 143. doi:10.4172/2167-1044.1000143

16. Langford DJ, Crager SE, Shehzad Z, Smith SB, Sotocinal SG, et al. (2006) Social modulation of pain as evidence for empathy in mice. Science 312: 1967 1970.

17. Chen Q, Panksepp JB, Lahvis GP (2009) Empathy is moderated by genetic background in mice. PLoS One 4: e4387.

18. Jeon D, Kim S, Chetana M, Jo D, Ruley HE, et al. (2010) Observational fear learning involves affective pain system and Cav1.2 Ca2+ channels in ACC. Nat Neurosci 13: 482-488.

19. Siegmund A, Wotjak CT (2007) A mouse model of posttraumatic stress disorder that distinguishes between conditioned and sensitised fear. J Psychiatr Res 41: $848-860$

20. Thoeringer CK, Henes K, Eder M, Dahlhoff M, Wurst W, et al. (2012) Consolidation of remote fear memories involves Corticotropin-Releasing Hormone (CRH) receptor type 1-mediated enhancement of AMPA receptor GluR1 signaling in the dentate gyrus. Neuropsychopharmacology 37: 787-796.

21. Yehuda R, Antelman SM (1993) Criteria for rationally evaluating animal models of posttraumatic stress disorder. Biol Psychiatry 33: 479-486.

22. American Psychiatric Association (2000) Diagnostic and statistical manual of mental disorders, text revision (4th edn)

23. Grillon C, Southwick SM, Charney DS (1996) The psychobiological basis of posttraumatic stress disorder. Mol Psychiatry 1: 278-297.

24. Siegmund A, Wotjak CT (2007) Hyperarousal does not depend on traumarelated contextual memory in an animal model of Posttraumatic Stress Disorder. Physiol Behav 90: 103-107.

25. Golub Y, Mauch CP, Dahlhoff M, Wotjak CT (2009) Consequences of extinction training on associative and non-associative fear in a mouse model of Posttraumatic Stress Disorder (PTSD). Behav Brain Res 205: 544-549.

26. Pamplona FA, Henes K, Micale V, Mauch CP, Takahashi RN, et al. (2011) Prolonged fear incubation leads to generalized avoidance behavior in mice. $J$ Psychiatr Res 45: 354-360.

27. Siegmund A, Dahlhoff M, Habersetzer U, Mederer A, Wolf E, et al. (2009) Maternal inexperience as a risk factor of innate fear and PTSD-like symptoms in mice. J Psychiatr Res 43: 1156-1165.

28. Sauerhöfer E, Pamplona FA, Bedenk B, Moll GH, Dawirs RR, et al. (2012) Generalization of contextual fear depends on associative rather than nonassociative memory components. Behav Brain Res 233: 483-493.

29. Dahlhoff M, Siegmund A, Golub Y, Wolf E, Holsboer F, et al. (2010) AKT/ GSK-3beta/beta-catenin signalling within the hippocampus and amygdala reflects genetically determined differences in posttraumatic stress disorder like symptoms. Neuroscience, 169: 1216-1226.

30. Golub Y, Kaltwasser SF, Mauch CP, Herrmann L, Schmidt U, et al. (2011) Reduced hippocampus volume in the mouse model of Posttraumatic Stress Disorder. J Psychiatr Res 45: 650-659.

31. Kamprath K, Wotjak CT (2004) Nonassociative learning processes determine expression and extinction of conditioned fear in mice. Learn Mem 11: 770-786.

32. Coudereau JP, Debray M, Monier C, Bourre JM, Frances H (1997) Isolation impairs place preference conditioning to morphine but not aversive learning in mice. Psychopharmacology (Berl) 130: 117-123.

33. Giardini V (1985) Influence of housing conditions and state of partner on conditioning and extinction of taste aversion to lithium and chlorpromazine. Psychopharmacology (Berl) 86: 96-101.

34. Kogan JH, Frankland PW, Silva AJ (2000) Long-term memory underlying hippocampus-dependent social recognition in mice. Hippocampus 10: 47-56.

35. Rudy JW (1996) Postconditioning isolation disrupts contextual conditioning: an experimental analysis. Behav Neurosci 110: 238-246.

Citation: Thoeringer CK, Wotjak CT (2013) Evaluating Social Support-Like Phenomena in an Animal Model of Posttraumatic Stress Disorder (PTSD) J Depress Anxiety 3: 143. doi:10.4172/2167-1044.1000143
36. Ferrari PF, Palanza P Parmigiani S, Rodgers RJ (1998) Interindividual variability in Swiss male mice: relationship between social factors, aggression, and anxiety. Physiol Behav 63: 821-827.

37. Palanza P (2001) Animal models of anxiety and depression: how are females different? Neurosci Biobehav Rev 25: 219-233.

38. Pietropaolo S, Singer P, Feldon J, Yee BK (2008) The postweaning social isolation in C57BL/6 mice: preferential vulnerability in the male sex. Psychopharmacology (Berl) 197: 613-628.

39. Bartolomucci A, Pederzani T, Sacerdote P, Panerai AE, Parmigiani $S$, et al. (2004) Behavioral and physiological characterization of male mice under chronic psychosocial stress. Psychoneuroendocrinology 29: 899-910.

40. Arndt SS, Laarakker MC, van Lith HA, van der Staay FJ, Gieling E, et al. (2009) Individual housing of mice--impact on behaviour and stress responses. Physio Behav 97: 385-393.

41. Kikusui T, Winslow JT, Mori $Y$ (2006) Social buffering: relief from stress and anxiety. Philos Trans R Soc Lond B Biol Sci 361: 2215-2228.

42. Knapska E, Nikolaev E, Boguszewski P, Walasek G, Blaszczyk J, et al. (2006) Between-subject transfer of emotional information evokes specific pattern of amygdala activation. Proc Natl Acad Sci U S A 103: 3858-3862.

43. Olsson A, Phelps EA (2007) Social learning of fear. Nat Neurosci 10: 1095 1102.

44. Insana SP, Wilson JH (2008) Social buffering in rats: prolactin attenuation of active interaction. Psychol Rep 103: 77-87.

45. Kiyokawa, Y, Takeuchi Y, Nishihara M, Mori Y (2009) Main olfactory system mediates social buffering of conditioned fear responses in male rats. European Journal of Neuroscience 29: 777-785.

46. Thoeringer CK, Erhardt A, Sillaber I, Mueller MB, Ohl F, et al. (2010) Long-term anxiolytic and antidepressant-like behavioural effects of tiagabine, a selective GABA transporter-1 (GAT-1) inhibitor, coincide with a decrease in HPA system activity in C57BL/6 mice. J Psychopharmacol 24: 733-743.

47. Radulovic J, Kammermeier J, Spiess J (1998) Generalization of fear responses in C57BL/6N mice subjected to one-trial foreground contextual fear conditioning Behav Brain Res 95: 179-189.

48. Koch M (1999) The neurobiology of startle. Prog Neurobiol 59: 107-128

49. Shalev AY, Peri T, Brandes D, Freedman S, Orr SP, et al. (2000) Auditory startle response in trauma survivors with posttraumatic stress disorder: a prospective study. Am J Psychiatry 157: 255-261.

50. Grillon C, Pine DS, Lissek S, Rabin S, Vythilingam M (2009). Increased anxiety during anticipation of unpredictable aversive stimuli in posttraumatic stress disorder but not in generalized anxiety disorder. Biological Psychiatry 66: 4753.

51. Eibl-Eibesfeldt I (1950) Beitrge zur Biologie der Haus- und Ã,hrenmaus nebst einigen Beobachtungen an anderen Nagern. Zeitschriftr Tierpsychologie, 7 : 558-587.

52. Sanders J, Mayford M, Jeste D (2013) Empathic fear responses in mice are triggered by recognition of a shared experience. PLoS One 8: e74609.

Submit your next manuscript and get advantages of OMICS Group submissions

Unique features:

User friendly/feasible website-translation of your paper to 50 world's leading languages Audio Version of published paper

Digital articles to share and explore

Special features:

300 Open Access Journals

25,000 editorial team

21 days rapid review process

Quality and quick editorial, review and publication processing

Indexing at PubMed (partial), Scopus, DOAJ, EBSCO, Index Copernicus and Google Scholar etc

Sharing Option: Social Networking Enabled

Authors, Reviewers and Editors rewarded with online Scientific Credits

Better discount for your subsequent

Submit your manuscript at: www.omicsgroup.org/iournals/submission/ 